J Am Coll Radiol. 2008 July ; 5(7): 853-855. doi:10.1016/j.jacr.2008.04.003.

\title{
Turning Up the Heat on MRI
}

\author{
Paul A. Bottomley, PhD \\ Division of MR Research, Park Building Room 310, Department of Radiology and Radiological \\ Science, Johns Hopkins University, 600 N Wolfe Street, Baltimore, MD 21287; \\ bottoml@mri.jhmi.edu.
}

In 2004, more than 22,000 magnetic resonance imaging (MRI) scanners performed some 65 million studies worldwide, with about half done in the United States. Magnetic resonance imaging has a stellar safety record and is not considered a significant risk. However, it is not hazard free. The worst danger is probably the projectile risk of magnetic objects being sucked into the main magnet, which is dealt with by diligent screening and control of access. Less dramatically, perhaps, is radiofrequency (RF) power deposition and heating in the body due to the MRI excitation field. Power deposition is measured by the specific absorption rate (SAR) in watts per kilogram or by direct thermometry. A third hazard, related to both of these, is the effect of an MRI scanner on devices and leads that are implanted in patients. These may move if they are magnetic, sustain damage from the applied fields, or heat if they incorporate electrically conducting materials. This hazard has traditionally been dealt with by excluding patients with conducting or magnetic implants entirely. However, the burgeoning number of patients with implants who need MRI is driving the development of MRI-safe implants and lead systems.

The mechanism for heating is the induction of eddy currents due to the nonzero conductivity of tissue via Faraday's law. Homogeneous tissue models have long shown that the SAR varies approximately as the square of both MRI frequency (or field strength) and sample radius, with maximum local SAR and heating at the surface [1]. However, these models do not accurately predict the SAR distribution in the body, which is composed of a heterogeneous distribution of tissues with different electrical properties.

The safety of RF exposure during clinical MRI is regulated by the US Food and Drug Administration [2] and the International Electrotechnical Commission's [3] guidelines for RF exposure adopted in Europe, which are summarized in Table 1. The burden of implementing these limits has, to date, fallen on MRI scanner manufacturers.

The problem for manufacturers is that the SAR is as much a property of the subject being scanned as it is a property of the scanner. To abide by regulatory SAR limits, scanner manufacturers must assume some tissue model of the body to derive the local maximum SAR, above which maximum heating and possible burns may occur. On the other hand, manufacturers do know, or could know, exactly how much power in total watts their scanners deposit into subjects. This is the RF power going into the MRI coil at its input minus the power dissipated in the coil. The weight of a subject (in kilograms) can be entered by a technologist at the MRI console. Thus, the whole-body SAR in Table 1 is just the total power divided by the weight. This sounds simple enough, so what's the problem?

A few years ago, we began safety-testing intravascular MRI coils fabricated from nitinol, an alloy commonly used for interventional catheters, with some gold coating included to improve the conductivity for use with 3-T MRI. We used a large phantom instrumented with fiber-optic temperature sensors, with one located remotely to measure the applied SAR. Because a watt can be defined in terms of degrees Celsius, the SAR is obtained directly from 
the time rate of temperature change. We observed that the thermal SAR was a lot lower than the value reported by the scanner. After finding disagreement between the "scanner SAR" and the thermal SAR in several scanners, it seemed that the scanner manufacturers had applied various unknown safety or modeling factors to the value reported by the instruments. Thus, because the differences were conservative (higher than they actually were), the manufacturers seemed to be erring on the side of safety for clinical MRI studies.

Unfortunately, these differences do mean that the scanner SAR cannot be used for MRI safety testing of implanted devices, for which, to be conservative, the applied SAR should, if anything, err on the high side, not the low side. Simply stated, a device testing safe at a scanner SAR of, say, $4 \mathrm{~W} / \mathrm{kg}$ will not, in fact, have been tested at $4 \mathrm{~W} / \mathrm{kg}$ if this is based on a value reported by the scanner that is overstated by a safety factor of 2 or so. Two recent studies $[4,5]$ testing implanted devices reported similar conclusions that "console-reported SAR does not constitute a reliable index of heating." So, with our trust in scanner SAR undermined, some colleagues and I began to explore the construction of an "SAR dosimeter" that might be used to set the RF power level of an MRI scanner for testing implanted devices [6].

About that time, our medical physicist asked me about some cases of burns or burning sensations reported by patients undergoing MRI at our institution. These cases seemed to exemplify situations in which at least the local SAR was anomalously high. In most, there was no association with the presence of other coils, external leads, or implants. The cases were investigated, and the manufacturer's MRI service engineers were called. They invariably reported that the scanner was operating normally or within specifications, but we had no independent way of checking the SAR, except for the ongoing dosimeter project [6]. A colleague then referred us to a Food and Drug Administration Web site that includes a database of voluntary individual reports of injuries occurring during MRI [7], of which we were unaware. About 40 MRI-associated skin or surface burns were reported in 2005 and 2006 [6], about $50 \%$ of which were not linked to any extraneous leads, separate surface coils, and so on. In such documented cases of burns, one must conclude that the local SAR was anomalously high or that protection was inadequate. Unfortunately, because the database is voluntary and not widely known, the actual incidence of burns is not accurately known.

Thus, although this news may be a surprise after 30 years of MRI, heating and SAR dosimetry during MRI are clearly both ongoing stories in the sense that MRI-associated burns continue to occur, and the accuracy of current scanner-based SAR estimates is at least questionable. The push to higher magnetic fields and the emergence of 3-T clinical scanners may increase the burn incidence rate, although it must be remembered that the SAR guidelines as set (see Table 1) are not field dependent. Thus, the event rate for new higherfield scanners may depend on the models chosen by manufacturers to relate peak to average SAR. If scanner manufacturers' response is to impose even more conservative scanner dosimetry, they risk negatively affecting the utility of the higher field by limiting scanner performance for routine high-SAR sequences, such as steady-state free precession, that perform so well at lower fields.

Our view of the way forward as we move to higher fields is that users will increasingly need to share responsibility for SAR dosimetry, just as they do for dosimetry in other radiologic imaging modalities monitored by medical physicists. In return, for researchers needing to know the true SAR for setting scanner exposure for testing implanted devices, as well as whether various SAR-intense MRI pulse sequences are safe, scanner manufacturers need to tell us exactly how many watts their scanners put into the sample at the time of the study, with this value not to be based on measurements on MRI coils made years earlier when they 
left the factory or other assumed system specifications. Meanwhile, the field needs to know the true incidence of MRI-associated burns. The most effective immediate response would be for all of us in the field to make sure that all such cases are reported to the Food and Drug Administration [7].

Finally, one must again stress the extraordinary safety record of this modality, with reported injuries representing but a minuscule fraction of clinical MRI studies.

\section{REFERENCES}

1. Bottomley PA, Roemer RB. Homogeneous tissue model estimates of RF power deposition in human NMR studies. Local elevations predicted in surface coil decoupling. Ann NY Acad Sci 1992;649:144-159. [PubMed: 1580488]

2. US Food and Drug Administration. Guidance for industry and FDA staff: criteria for significant risk investigations of magnetic resonance diagnostic devices. [Accessed May 20, 2008]. Available at: http://www.fda.gov/cdrh/ode/guidance/793.pdf.

3. European Committee for Electrotechnical Standardization. Particular requirements for the safety of magnetic resonance equipment for medical diagnosis (IEC 60601-2-33:2002). Brussels, Belgium: European Committee for Electrotechnical Standardization; 2002.

4. Baker KB, Tkach JA, Nyenhuis JA, et al. Evaluation of specific absorption rate as a dosimeter of MRI-related Implant Heating. J Magn Reson Imaging 2004;20:315-320. [PubMed: 15269959]

5. Baker KB, Tkach JA, Phillips M, Rezai AR. Variability in RF-induced heating of a deep brain stimulation implant across MR systems. J Magn Reson Imaging 2006;24:1236-1242. [PubMed: 17078088]

6. Stralka JP, Bottomley PA. A prototype RF dosimeter for independent measurement of the average specific absorption rate (SAR) during MRI. J Magn Reson Imag 2007;26:1296-1302.

7. US Food and Drug Administration, Center for Devices and Radiological Health. Manufacturer and User Facility Device Experience Database-(MAUDE). [Accessed May 20, 2008]. Available at: http://www.accessdata.fda.gov/scripts/cdrh/cfdocs/cfMAUDE/TextSearch.cfm. 
Table 1

IEC and FDA guidelines on SAR and heating in human MRI studies

\begin{tabular}{|llccc|}
\hline Limit & $\begin{array}{l}\text { Whole-Body } \\
\text { Average }\end{array}$ & $\begin{array}{c}\text { Heat } \\
\text { Average }\end{array}$ & $\begin{array}{c}\text { Head, Trunk } \\
\text { Local SAR }\end{array}$ & $\begin{array}{c}\text { Extremities } \\
\text { Local }\end{array}$ \\
\hline IEC (6-minute average) & & & & \\
Normal (all patients) & $2 \mathrm{~W} / \mathrm{kg}\left(0.5^{\circ} \mathrm{C}\right)$ & $3.2 \mathrm{~W} / \mathrm{kg}$ & $10 \mathrm{~W} / \mathrm{kg}$ & $20 \mathrm{~W} / \mathrm{kg}$ \\
First level (supervised) & $4 \mathrm{~W} / \mathrm{kg}\left(1^{\circ} \mathrm{C}\right)$ & $3.2 \mathrm{~W} / \mathrm{kg}$ & $10 \mathrm{~W} / \mathrm{kg}$ & $20 \mathrm{~W} / \mathrm{kg}$ \\
Second level (IRB approval) & $4 \mathrm{~W} / \mathrm{kg}\left(>1^{\circ} \mathrm{C}\right)$ & $>3.2 \mathrm{~W} / \mathrm{kg}$ & $>10 \mathrm{~W} / \mathrm{kg}$ & $>20 \mathrm{~W} / \mathrm{kg}$ \\
Localized heating limit & $39^{\circ} \mathrm{C} \mathrm{in} 10 \mathrm{~g}$ & $38^{\circ} \mathrm{C}$ in $10 \mathrm{~g}$ & & $40^{\circ} \mathrm{C}$ in $10 \mathrm{~g}$ \\
FDA & $4 \mathrm{~W} / \mathrm{kg} \mathrm{for}$ & $3 \mathrm{~W} / \mathrm{kg}$ for & $\begin{array}{c}8 \mathrm{~W} / \mathrm{kg} \mathrm{in} 1 \mathrm{~g} \\
\text { for } 10 \mathrm{~min}\end{array}$ & $\begin{array}{c}12 \mathrm{~W} / \mathrm{kg} \mathrm{in} 1 \mathrm{~g} \\
\text { for } 5 \mathrm{~min}\end{array}$ \\
\hline
\end{tabular}

Note: FDA = US Food and Drug Administration; IEC = International Electrotechnical Commission; IRB = institutional review board; MRI = magnetic resonance imaging; $\mathrm{SAR}=$ specific absorption rate.

Source: FDA [2], European Committee for Electrotechnical Standardization [3]. 